\title{
OS DESAFIOS DO ESTATUTO DA CIDADE FRENTE À INFLEXÃO ULTRA LIBERAL E O DESMONTE DA POLÍTICA URBANA BRASILEIRA
}

The challenges of the Estatuto da Cidade in the face of the ultra liberal inflection and the dismantling of brazilian urban policy

\section{João Telmo de Oliveira Filho}

joaotelmofilho@gmail.com

Afiliação: Programa de Pós Graduação em Gestão de Organizações Públicas - Universidade Federal de Santa Maria. Santa Maria, RS.

Titulação: Advogado, Doutor em planejamento urbano e regional pelo PROPUR/UFRGS, pós-doutor em Direito pela Universidade de Coimbra - Portugal.

\section{Tarcyla Fidalgo Ribeiro}

tarcylafidalgo@gmail.com

Afiliação: Observatório das Metrópoles, Rio de Janeiro, RJ, Brasil.

Titulação: Advogada, Doutora em política e planejamento urbano e regional pelo IPPUR/UFRJ

\section{RESUMO}

O presente artigo tem como objetivo abordar e discutir algumas das recentes iniciativas legislativas que buscam alterar a legislação urbanística brasileira, em especial o capítulo da política urbana na Constituição Federal de 1988 e às diretrizes e princípios da política urbana presentes no Estatuto da Cidade (Lei 10.257/01). Inicia discutindo os princípios e diretrizes da política urbana na Constituição Federal de 1988 e no Estatuto da Cidade e as recentes alterações na legislação urbanística e na política urbana. Inclui a análise das principais iniciativas legislativas divididas entre normas aprovadas e projetos legislativos em tramitação no Congresso Nacional, a partir do ano de 2017, fundados na alteração da política fundiária e na disseminação do princípio da liberdade econômica na ordem urbana nacional. Entre as normas aprovadas estão a Lei 13.465/17; Lei 13.813/19; Lei 14.011/20, a Medida Provisória n. 910/18 convertida no Projeto de Lei 2633/20 - a “MP da Grilagem”. Entre os projetos em tramitação analisados estão a Proposta de Emenda à Constituição n. 80/19, o Projeto de Lei 413/2019 e a Resolução CGSIM n. 64/20, do Ministério da Economia. Como conclusão, algumas considerações e apontamentos sobre essas iniciativas e tendências no âmbito da política urbana brasileira.

Palavras-chave: Estatuto da Cidade. Constituição Federal. Política Urbana. Regularização Fundiária. Iniciativas Legislativas.

\section{ABSTRACT}

This article aims to discuss some of the recent legislative initiatives that are changing the Brazilian urban legislation, specialy the urban policy chapter in the Federal Constitution of 1988 and the urban policy guidelines and principles of the Estatuto da Cidade (Lei 10.257/01). It begins by discussing the principles and guidelines of urban policy in the Federal Constitution of 1988 and in the Cities' Statute, and then, the recent changes in urban legislation and urban order. It includes the analysis of the main 
legislative initiatives both in approved norms and in still-in-progress legislative projects, as of 2017, based on the changes in land policy views and on the dissemination of free-market economy in the national urban policy. Among the approved regulations are the Lei 13.465/17; Lei 13.813/19; Lei 14.011/20, a Medida Provisória n. 910/18 converted into Projeto 2633/20 - the "MP da Grilagem" [Land Grabbing Provisional Measure]. Among the analyzed projects there are the a Proposta de Emenda à Constituição n. 80/19, o Projeto de Lei 413/2019 and CGSIM Resolução n. 64/20, of the Ministry of Economy. In conclusion, some notes on these initiatives and overrall trends in the scope of Brazilian urban policy.. Keywords: Estatuto da Cidade. Constituição Federal. Urban Policy. Land regularization. Legislative Initiatives.

\section{INTRODUÇÃO}

Este artigo tem como objetivo informar e discutir muitas das recentes iniciativas legislativas que buscam alterar boa parte da legislação urbanística brasileira, especialmente o capítulo da política urbana na Constituição Federal de 1988 e o Estatuto da Cidade (Lei 10.257/01) em um processo de legitimação da inflexão ultra liberal e de ataques às diretrizes e princípios da política urbana, afrontando direitos e conquista sociais.

A partir de 2017, múltiplos são os ataques à ordem urbana nacional conforme prevista na Constituição Federal e no Estatuto da Cidade. O cenário de aprofundamento do neoliberalismo e da financeirização no país, somado à disseminação de uma ideologia conservadora, individualista e empreendedora, vem colocando em risco crescente a busca por cidades mais justas e igualitárias.

Nesse contexto, o artigo inicia com considerações sobre os princípios constitucionais e diretrizes normativas da política urbana brasileira presentes na Constituição Federal de 1988 e no Estatuto da Cidade e sobre a inflexão ultraliberal e os recentes ataques à legislação urbanística e à política urbana. Segue com a análise das principais iniciativas legislativas neste contexto, divididas entre normas aprovadas e projetos legislativos em tramitação no Congresso Nacional, a partir do ano de 2017, primeiro ano após o golpe jurídico parlamentar que marcou a inflexão conservadora e ultraliberal no Brasil e tendo dois eixos temáticos como guia: a política fundiária e a disseminação do princípio da liberdade econômica na ordem urbana nacional. Dentre as normas analisadas estão as leis aprovadas: Lei 13.465/17; Lei 13.813/19; Lei 14.011/20, a Medida Provisória n. 910/18 convertida no Projeto de Lei 2633/20 conhecida como "MP da Grilagem”. Entre os projetos em tramitação estão a Proposta de Emenda à Constituição n. 80/19, o Projeto de Lei 413/2019 e a Resolução CGSIM n. 64/20, do Ministério da Economia.

Por fim, o artigo traz algumas considerações e apontamentos sobre e a partir desses processos, buscando identificar as tendências futuras no âmbito da política urbana brasileira e ampliando a discussão sobre o tema.

\section{DESENVOLVIMENTO}

\subsection{Os princípios constitucionais e diretrizes normativas da política urbana brasileira presentes no Estatuto da Cidade}

Resultado de muitos anos de discussão e da pressão dos movimentos sociais na redemocratização do país na década de 1980, a Constituição Federal brasileira descreve um capítulo próprio para a "política urbana”, no título da Ordem Econômica e Financeira, com os artigos 182 e 183. Refere o artigo 
182 que a "política de desenvolvimento urbano", tem como objetivo "ordenar o pleno desenvolvimento das funções da cidade" e "garantir o bem estar dos seus habitantes". No parágrafo segundo do mesmo artigo 182 diz que a propriedade urbana cumpre sua função social quando atende às exigências de ordenação da cidade expressa no plano diretor municipal. (BRASIL, 1988)

\section{CONSTITUIÇÃO DA REPÚBLICA FEDERATIVA DO BRASIL.}

Art. 182. A política de desenvolvimento urbano, executada pelo Poder Público municipal, conforme diretrizes gerais fixadas em lei, tem por objetivo ordenar o pleno desenvolvimento das funções sociais da cidade e garantir o bem- estar de seus habitantes.

(...)

$\$ 2^{\circ}$ A propriedade urbana cumpre sua função social quando atende às exigências fundamentais de ordenação da cidade expressas no plano diretor.

No sistema de repartição de competências estabelecido pela Constituição Federal de 1988, no âmbito da competência concorrente sobre direito urbanístico, a União tem atribuição de estabelecer as normas gerais por meio de lei federal de desenvolvimento urbano. Esta lei deve conter as diretrizes do desenvolvimento urbano e regional, os objetivos da política urbana nacional, a regulamentação dos artigos 182 e 183 da Constituição, além de instituir os instrumentos urbanísticos e o sistema de gestão desta política.

O Estatuto da Cidade é a lei federal de desenvolvimento urbano prevista na Constituição. Entre os princípios jurídicos e políticos que norteiam o Estatuto da Cidade cumpre destacar os da "função social da cidade e o da propriedade urbana e os da participação popular e da gestão democrática da cidade", o da "sustentabilidade" o da "cooperação intergovernamental", dentre outros previstos no seu artigo segundo. (BRASIL, 2001).

A identificação das normas do Estatuto da Cidade como regras gerais, estabelece a adequação destas normas aos princípios da Constituição Federal, vinculando, tanto o legislador, como o administrador, no sentido de realizar as tarefas constitucionais prescritas.

A aplicabilidade imediata do princípio da função social da propriedade urbana se dá tanto pela leitura do artigo $5^{\circ}$, parágrafo primeiro da Constituição Federal, quanto pelas próprias regras prescritas no Estatuto da Cidade, que assegura o direito à propriedade urbana, desde que cumprida a sua função social, determinada pela legislação urbanística conforme diretrizes do plano diretor municipal, sendo que o plano diretor deve ser elaborado de forma democrática e com a participação popular.

Entretanto, nos últimos anos, o Estatuto da Cidade e a legislação urbana e ambiental como um todo tem sofrido ataques sistemáticos em um cenário de ampliação no poder de movimentos conservadores, com o golpe parlamentar de 2016 e a ascensão ao poder da extrema direita em 2018 na presidência da República, nos governos estaduais e no congresso nacional e que patrocinam o desmonte de políticas sociais. Neste contexto, uma série de iniciativas legislativas buscam desregulamentar e suprimir princípios e diretrizes da política urbana democrática.

O presente artigo irá abordar algumas dessas medidas legais, buscando compreender os mecanismos pelos quais o direito vem sendo acionado como mecanismo de legitimação dessa inflexão que atinge a política urbana brasileira. Inicia com uma discussão sobre a inflexão ultra liberal e ataques à 
política urbana e segue a análise das iniciativas legislativas dividindo em normas aprovadas e projetos legislativos em tramitação no Congresso Nacional, a partir do ano de 2017.

Para fins de recorte temático, abordaremos iniciativas no âmbito fundiário e relacionadas com a crescente tentativa de submissão do sistema normativo urbanístico nacional ao recém positivado princípio da liberdade econômica. Entre tais iniciativas tentando "passar a boiada" na legislação urbana e ambiental estão as leis aprovadas: Lei 13.465/17 e a Lei 13.813/19, que dispõe sobre a transferência e gestão de dois significativos estoques fundiários e imobiliários da União, a Lei 14.011/20 que aprofunda as possibilidades do processo de privatização de terras e imóveis da União e a Medida Provisória n. 910/18 convertida no Projeto de Lei 2633/20 conhecida “MP da Grilagem”. Entre os projetos em tramitação estão a PEC 80/2019 que busca alterar o artigo 182 da Constituição Federal, o PL 413/2019 que altera o Estatuto da Cidade e a Lei de Parcelamento Urbano e a Resolução CGSIM n. 64/20, do Ministério da Economia, que propõe a flexibilização do licenciamento urbanístico nas cidades brasileiras.

\subsection{A inflexão ultra liberal e os ataques à política urbana}

A partir do ano de 2016 podemos falar de um cenário de inflexão ultraliberal e conservadora em nosso país. Tendo como marco o golpe jurídico parlamentar que tirou do poder a então presidenta eleita Dilma Rousseff, pode-se falar de um processo de aprofundamento da inserção do país em um cenário global de financeirização e neoliberalismo.

Esses processos, na periferia, são marcados por medidas de austeridade, desindustrialização, redução dos direitos do trabalhador e da seguridade social. No âmbito social, observa-se o crescimento de uma ideologia baseada em valores como a meritocracia e o empreendedorismo (DARDOT e LAVAL, 2016).

Esse cenário de individualismo exacerbado e redução dos sistemas de proteção social é propício para o florescimento de grupos conservadores como os que ganharam poder no executivo federal, especialmente a partir das eleições de 2018.

Essa tempestade perfeita criada a partir do aprofundamento dos valores e práticas neoliberais somados à ascensão de grupos conservadores ao poder levou a um cenário de aceleração de reformas públicas no sentido da redução de direitos e aumento de processos de privatização, sempre ligados ao discurso da austeridade e da suposta necessidade de uma redução da participação do Estado na economia e na vida social.

No âmbito da política urbana os rebatimentos desse cenário vêm sendo sentidos em diversas dimensões: desde tentativas legais de reforço da ideologia proprietária em detrimento da perspectiva da função social, passando por medidas de funcionalização das cidades para o processo crescente de financeirização do país, até o crescimento das desigualdades socioespaciais.

No âmbito ideológico, estamos diante de um processo de imposição de uma visão de cidade oposta àquela trazida pela Constituição Federal e pelo Estatuto da Cidade. Ao invés de um espaço de justiça e solidariedade, compartilhamento e debate de ideias, as cidades passam a ser vistas como meio de acumulação de capital, polarização, violência e como um espaço no qual indivíduos apenas se suportam, cada um buscando tirar o melhor proveito de sua posição, social e territorial. 
Um dos principais aspectos dessa inflexão no âmbito da ideologia constituída em torno do urbano está nas sucessivas tentativas de submissão da ordem urbanística ao recém positivado princípio da liberdade econômica. Trata-se de uma perspectiva sobre as cidades pela qual estas se configuram, como visto, em meros espaços de convívio que não devem atrapalhar as iniciativas e liberdades individuais. É a cidade do eu, e não do nós, que a referida inflexão quer estabelecer em nosso país.

Neste contexto, uma série de medidas legais são lançadas no processo de desregulamentar o modelo de cidade e desenvolvimento urbano vigente desde 1988, a partir da construção de um modelo que se coadune com os valores do individualismo, conservadorismo e empreendedorismo, atualmente dominantes na lógica governamental brasileira. Veremos a seguir algumas destas ações divididos entre iniciativas já aprovadas e com status de lei e outras que ainda se conformam como projetos em fase de tramitação e debates.

\subsection{As normas aprovadas e os projetos legislativos: as tentativas de desmonte da política urbana.}

\subsubsection{Iniciativas legislativas aprovadas: Da Lei 13.465/17 a MP da grilagem de terras.}

No âmbito fundiário rural e urbano, a inflexão acima retratada foi cristalizada pela aprovação da Lei 13.465 (BRASIL, 2017), a partir da conversão da Medida Provisória n. 759 (BRASIL, 2016). A referida lei alterou drasticamente o paradigma da regularização fundiária no país, privilegiando a titulação em detrimento das demais medidas urbanísticas, ambientais, administrativas e sociais que informaram a regularização fundiária sob o paradigma anterior. Para além do privilégio da titulação, a referida lei também buscou facilitar a privatização do estoque fundiário público nacional - medida que será aprofundada pela Lei 13.813 (BRASIL, 2019), como veremos adiante.

Por trás dessa inflexão legislativa, é possível identificar interesses nacionais e internacionais na homogeneização do estoque fundiário nacional sob o paradigma da propriedade privada capitalista, de modo a permitir uma nova rodada de mercantilização e colocar as condições para a crescente transformação da terra em ativo financeiro no Brasil (RIBEIRO, 2021). Além disso, há conexões claras com interesses de regularização de áreas griladas e privatização de imóveis públicos a preços que permitam a obtenção de lucros extraordinários por agentes imobiliários.

Essa última motivação da inflexão cristalizada pela Lei 13.465 (BRASIL, 2017) se reafirma, no ano seguinte, pela edição da Medida Provisória n. (BRASIL, 2018), posteriormente convertida na Lei 13.813 (BRASIL, 2019). Esta Lei dispõe sobre a transferência e gestão de dois significativos estoques fundiários/imobiliários da União: os imóveis da extinta Rede Ferroviária Federal S/A - RFFSA e os imóveis do Fundo do Regime Geral de Previdência Social, para entes privados.

$\mathrm{Na}$ linha do estímulo à transferência de terras/imóveis públicos já estabelecida na Lei 13.465 (BRASIL, 2017), a Lei 13.813 (BRASIL, 2019) detalha os procedimentos e possibilidades para os dois estoques fundiários/imobiliários acima descritos. Trata-se de regulação que estabelece condições favoráveis para a alienação para particulares, além de prever a utilização de imóveis para a integralização de fundos de investimentos, a serem criados às custas da União.

A previsão da privatização de imóveis públicos via fundo de investimento é a principal novidade trazida pela referida lei, tornando mais evidentes os nexos entre a disseminação da propriedade pri- 
vada e os interesses de agentes capitalistas ligados ao mercado financeiro, afinados com o cenário de dominância financeira internacional.

Ainda sob a mesma motivação ligada à facilitação da transferência de imóveis públicos, temos a Medida Provisória 915 (BRASIL, 2019), posteriormente convertida na Lei 14.011 (BRASIL, 2020). Trata-se de mais uma regulação sobre a gestão e alienação de imóveis da União, embora de abrangência mais ampla e mais detalhada que a Lei 13.813 (BRASIL, 2019) apresentada anteriormente. A referida Lei aprofunda as possibilidades do processo de privatização de terras/imóveis da União, possibilitando a realização de avaliação com base em plantas de valores (notadamente defasadas) sem visita presencial e autorizando a concessão de descontos. Além disso, trata expressamente da preferência geral pela venda dos imóveis/terras públicas, sem qualquer finalidade preferencial (como a habitação de interesse social), conforme previsto no art. 22, parágrafo 4.

Ainda no sentido do aprofundamento da privatização e financeirização do estoque imobiliário e fundiário, a Lei prevê a utilização da estrutura do BNDES para a realização de estudos e execução de plano de desestatização de ativos imobiliários da União (art. 24-D), além de garantir a possibilidade de que a desestatização se dê pela constituição e integralização de fundo de investimento imobiliário (art. 24-D, II). Ou seja: trata-se de submeter imóveis/ terras públicas ao regime da propriedade privada individual e, de uma só vez, ainda abrir as portas para seu ingresso nas dinâmicas financeiras, por meio de sua integralização em fundos de investimento imobiliário.

A última legislação que se pretende destacar aqui como exemplo da inflexão imposta no campo do direito urbanístico trata da temática da regularização fundiária em terras da União, com a finalidade de "ampliar seu alcance". Mais uma vez se está diante de uma regulação originada como Medida Provisória (n. 910 - BRASIL, 2019) que, não tendo sido apreciada pelo Congresso Nacional no prazo constitucional foi convertida em um Projeto de Lei, de n. 2633 (BRASIL, 2020). A referida MP ficou conhecida nos meios de comunicação como "MP da Grilagem" (OLIVEIRA, 2020 e FELLET, 2020) e sua conversão em projeto de lei por falta de aprovação do congresso no prazo já demonstra as controvérsias envolvidas em seu texto.

A justificativa apresentada em anexo ao texto do projeto de lei já se refere expressamente à regularização fundiária como instrumento de dinamização econômica, utilizando este fato como justificativa para sua disseminação territorial.

O referido projeto de lei, aprovado recentemente na Câmara dos Deputados, estabelece expressamente a alienação como forma preferencial de regularização em terras/imóveis da União (art. 2 e 6) e facilita a aquisição, por exemplo, pela previsão de pagamento de terras na Amazônia legal pelo valor da terra nua.

Mas o ponto principal do projeto, e o mais controverso, é a possibilidade de regularização fundiária por autodeclaração e sem vistoria prévia pelo INCRA em imóveis de até 6 módulos fiscais (art. 13). Cabe destacar que no norte do Brasil os módulos fiscais variam, em média, entre 70 e 110 hectares (INCRA, 2013) e que, portanto, estamos falando de áreas de 420 a 660 hectares passíveis de regularização pela simples declaração de posse, sem vistoria prévia do órgão público responsável - INCRA. Basta a declaração para que a pessoa (física ou jurídica) adquira a propriedade da área formalizada. 
Percebe-se porque a Medida Provisória convertida no Projeto de Lei recebeu o "apelido" de MP da grilagem. Sem dúvidas esse tipo de previsão estimula a prática de fraudes na região, visto que garante a formalização da propriedade sem qualquer verificação prática da declaração feita. Cabe destacar que no texto original da Medida Provisória a autodeclaração como modalidade de regularização fundiária era permitida para imóveis de até 15 módulos fiscais.

Para além do estabelecimento de uma modalidade auto declaratória de regularização - o ápice da estratégia iniciada pela Lei 13.465 (BRASIL, 2017) de estabelecimento de um modelo de regularização fundiária rápido, barato e que pudesse disseminar a propriedade privada individual no país - o referido projeto de lei também traz previsão expressa de estímulo à utilização dos imóveis/terras como garantia de crédito, mesmo que durante o pagamento do valor devido pela alienação (art. 15, parágrafos 1 e 7).

O referido projeto de lei foi aprovado pela Câmara dos Deputados em 03 de agosto de 2021 e segue para votação no Senado, com amplas chances de aprovação. Trata-se da consolidação da inflexão urbanística em curso no país desde o golpe jurídico parlamentar de 2016 no âmbito fundiário.

\subsubsection{Projetos em tramitação no Congresso Nacional}

Dentre as propostas legislativas em tramitação no Congresso Nacional está a Proposta de Emenda à Constituição 80 (SENADO FEDERAL, 2019), de autoria do senador Flávio Bolsonaro (Republicanos) e outros senadores, que propõe modificar o artigo 182 da Constituição Federal de 1988, especialmente em relação ao princípio da função social da propriedade urbana.

A proposta, que pretende se justificar sob o argumento de "estabelecer critérios para a aplicação da função social da propriedade" e "evitar arbitrariedades", inclui no texto do artigo 182 da CF a expressão "sem ofensa a direitos de terceiros" e estabelece que a função social da propriedade urbana só poderia ocorrer quando esteja presente "ao menos uma das seguintes exigências fundamentais de ordenação da cidade expressas no plano diretor: I- parcelamento ou edificação adequados; II- aproveitamento compatível com sua finalidade; III - preservação do meio ambiente ou do patrimônio histórico, artístico, cultural ou paisagístico". (SENADO FEDERAL, 2019)

Ao versar sobre a função social urbana, matéria reservada pela Constituição federal aos planos diretores municipais, o projeto afronta sua condição, também constitucionalmente estabelecida, de instrumento básico de planejamento e gestão do território, em uma proposta que fere a autonomia municipal.

O referido Projeto de Emenda Constitucional também estabelece que a função social da propriedade urbana "somente será declarada por ato do Poder Executivo, mediante autorização prévia do Poder Legislativo, ou por decisão judicial" (SENADO FEDERAL, 2019) atacando frontalmente o princípio da separação dos poderes e a competência para execução da política urbana pelo poder executivo municipal.

O parágrafo sexto acrescentado pelo projeto dispõe que "A desapropriação por descumprimento da função social será feita pelo valor de mercado da propriedade urbana" premiando o proprietário infrator ou que mantenha imóvel urbano para fins de especulação, obrigando a administração pública municipal a gastar recursos públicos para comprar imóvel objeto de especulação ao preço do mercado. 
Conforme Hermanny Giacobbo (2020, p. 2479) a proposta:

é suficiente para desfigurar o conteúdo jurídico da função social e impingir um retrocesso equivalente a um século de construção doutrinária e jurisprudencial com relação à responsabilidade do proprietário de um imóvel com o coletivo (...) Verifica-se que na tentativa de aproveitar o momento do avanço de forças conservadores e a nova correlação de forças no Congresso Nacional levou os principais representantes dos interesses corporativos, tanto na cidade - representado pelas grandes incorporadoras e proprietários dos escassos estoques de terra urbana - quanto no campo - notadamente pelo agronegócio e proprietários de latifúndios - a intentar suprimir, por via constitucional, o conteúdo da função social da propriedade. Não o fez, no entanto, se utilizando de justificativas científicas, históricas e empíricas minimamente razoáveis.

Assim, pelos argumentos aqui descritos, a PEC 80/2019 é flagrantemente inconstitucional pois fere princípios fundamentais expressos na Constituição Federal brasileira, especialmente o princípio federativo, a autonomia municipal e o princípio da função social da propriedade urbana. Apesar da flagrante inconstitucionalidade, a referida PEC segue em tramitação.

Outra proposta que merece destaque no sentido de denunciar o processo de desmonte da política urbana nacional é o Projeto de Lei 413 (BRASIL, 2020). Trata-se de uma das poucas propostas legislativas, de autoria dos Deputados Federais Vinícius Poit e Paulo Ganime (NOVO/SP); Kim Kataguire (DEM/SP) que não teve origem de uma Medida Provisória, não partindo, portanto, de um ato unilateral do chefe do poder executivo nacional.

O projeto busca alterar a Lei $10.257 / 2001$, a Lei $13.465 / 2017$ e a Lei 6.766/1979, instrumentos normativos que são leis gerais de direito urbanístico, cuja iniciativa legislativa é de competência exclusiva do poder executivo, violando também a diretriz de gestão democrática prevista no inciso II do art. $2^{\circ}$ do Estatuto da Cidade, segundo a qual a formulação de projetos que tenham relação com o desenvolvimento urbano deve contar com estudos técnicos e com a participação da população na elaboração.

A proposta submete diversos instrumentos do Estatuto da Cidade, à Declaração de Direitos de Liberdade Econômica (Lei 13.874/2019), além de incluir o instrumento da "gestão compartilhada", que terceiriza a gestão da política pública e permite também que lei ordinária municipal possa alterar diretrizes do parcelamento, edificação e uso do solo previstos no plano diretor.

Tem como objetivo declarado "alterar a regularização fundiária para ampliar o conjunto de alternativas para a titulação definitiva da propriedade privada" (BRASIL, 2020), estando claro o caráter de reforço e aprofundamento dos objetivos trazidos pela Lei 13.465 (BRASIL, 2017).

A justificativa apresentada ao projeto de lei associa diretamente a titulação fundiária à integração da população ao sistema bancário e financeiro formal, com destaque para a utilização do imóvel como garantia creditícia. A explicitação do vínculo entre terra e economia não poderia ser mais direta. A ideia do legislador é que a homogeneização do regime jurídico fundiário sob o paradigma da propriedade privada individual é uma ponte direta para o aquecimento do mercado de crédito e, em consequência, do mercado financeiro, por meio da securitização de títulos lastreados na terra.

Sob um aspecto analítico mais geral, é importante destacar que o referido projeto promove diversas alterações no Estatuto da Cidade - lei geral sobre política urbana - no sentido de submeter diversos dos seus instrumentos ao princípio da liberdade econômica, inaugurado em nosso ordenamento pela 
Lei 13.874 (BRASIL, 2019). Trata-se da positivação da supremacia de interesses privados na política urbana, em detrimento dos princípios do interesse público e da justiça social.

Essa submissão à liberdade econômica se expressa, no âmbito específico da regularização fundiária, na possibilidade de que esta seja integralmente realizada por ente privado, abrindo um novo mercado para agentes imobiliários e aumentando a possibilidade de disseminação de títulos, especialmente considerando a incapacidade econômica estatal característica do momento atual. Ainda sobre a possibilidade de realização da regularização fundiária por entes privados, o referido projeto permite que o próprio imóvel a ser regularizado seja dado em garantia da dívida decorrente do processo de regularização, no formato da alienação fiduciária.

Além disso, o projeto traz o incentivo à utilização do imóvel como garantia creditícia (art. 13- B), o que se coaduna com a ideia de que a irregularidade fundiária vem se apresentando como um "nó" para o desenvolvimento de um mercado financeiro lastreado na terra urbana.

Por fim, a última proposta a ser destacada nesta seção é a Resolução CGSIM n. 64, (MINISTÉRIO DA ECONOMIA, 2020), que "versa sobre a classificação de risco no direito urbanístico" e impacta diretamente na gestão municipal no que concerne ao licenciamento urbano, permitindo a flexibilização do licenciamento urbanístico nas cidades brasileiras. Em uma aparente complementação da Lei da Liberdade Econômica - Lei 13.874 (BRASIL, 2019)

A referida resolução pretendia promover a desregulamentação e flexibilização da política urbana nos diversos entes federativos, em uma violação do pacto federativo ao invadir a competência do município na ordenação e controle do uso do solo. Além disso, a resolução criava obrigações, exigindo que os municípios tivessem "legislação própria de direito urbanístico para a Lei no 13.874 " e "legislação própria de risco de baixo risco de direito urbanístico". No mérito, a resolução pretendia submeter as diretrizes do direito urbanístico a uma "classificação de risco" que, em conformidade com o princípio da liberdade econômica, permita uma flexibilização do licenciamento urbanístico nas cidades brasileiras.

Conforme Nota Técnica elaborada pelo Instituto Brasileiro de Direito Urbanístico - IBDU e outras entidades (IBDU, 2020b), ao fazer referência ao "direito urbanístico" a resolução se remete à matéria objeto de reserva de lei, não podendo de forma nenhuma ser objeto de uma resolução. Estas alterações apenas poderiam ser propostas e realizadas por meio de lei e jamais por resolução ministerial, o que mais uma vez expõe o vício de invasão de competência e iniciativa legislativa.

Ainda quanto ao mérito, a submissão do licenciamento urbanístico ao dogma da liberdade econômica estabelece uma "supremacia do interesse privado" sem qualquer fundamento jurídico que sustente tal pretensão, contrariando todos os princípios relacionados ao Direito administrativo, urbanístico e ambiental. (IBDU, 2020b)

No âmbito ambiental, a resolução altera a legislação existente no país sobre licenciamento, sem qualquer critério ou estudo técnico. Além disso, formula conceitos como o de "risco no direito urbanístico", e, ainda, possibilita que empresas privadas ofereçam os serviços de licenciamento, ferindo a competência dos municípios sobre o licenciamento urbanístico.

A partir da pressão de movimentos sociais, notas técnicas de entidades e de propostas de resolução de mesa de parlamentares, a resolução foi revogada pelo Ministério da Economia e um grupo de trabalho foi constituído para a elaboração de nova resolução, até o momento não elaborada. 


\section{CONCLUSÃO}

Todas as regulações aqui apresentadas, componentes do período de inflexão ultraliberal e conservadora que se inicia em 2016, com o golpe jurídico parlamentar que retirou do poder a presidenta Dilma Rousseff, convergem no sentido de um desmonte da ordem urbanística nacional no sentido de sua privatização, financeirização e neoliberalização, cuja expressão máxima são as tentativas de sua submissão ao princípio da liberdade econômica.

No âmbito fundiário, fica claro o objetivo do aprofundamento da proposta principal da Lei 13.465 (BRASIL, 2017), qual seja, aperfeiçoar a regularização fundiária como instrumento de disseminação de títulos de propriedade individual, permitindo uma homogeneização do regime jurídico fundiário e, como consequência, a formação de uma base sólida para operações creditícias e financeiras que envolvam a terra no Brasil. Cabe destacar que algumas regulações, inclusive, avançam diretamente no sentido da financeirização da terra, ao permitir que imóveis públicos sejam direcionados diretamente para Fundos de Investimento Imobiliário.

Esse grupo de normas e propostas aqui apresentadas além de sérias dúvidas quanto a legalidade e constitucionalidade representam um enorme retrocesso jurídico e refletem o pensamento e a prática política de desregulamentação e de diminuição do controle público e social da política urbana nos últimos anos, "abrindo a porteira" para todo e qualquer tipo de empreendimento de cunho privado que até então estivesse à margem da regulamentação.

Isso porque os objetivos da política urbana brasileira estabelecidos pela Constituição Federal e posteriormente pelo Estatuto da Cidade visam à justa distribuição da terra urbana, à correção das desigualdades territoriais e à implementação de políticas sociais, o que vem sendo paulatinamente atacado para atender a demandas de setores privados, subvertendo o caráter público da política urbana sob o discurso falacioso da liberdade econômica.

Neste cenário de desmonte e ataque à legislação urbana, com dificuldade de atuação da sociedade civil, é importante reafirmar os preceitos positivados no capítulo da política urbana da Constituição Federal e no Estatuto da Cidade, frutos de árdua luta de movimentos e instituições em busca de cidades mais justas e igualitárias no Brasil.

O papel dos operadores do direito neste cenário é reforçar os princípios e diretrizes políticas e sociais estabelecidas na Constituição Federal e no Estatuto da Cidade, com especial atenção às iniciativas legislativas que visam suprimir direitos constitucionalmente estabelecidos, invertendo a lógica da soberania do interesse público. As tendências futuras no âmbito da política urbana brasileira devem apontar na direção da ampliação do controle público e da participação social como forma de bloquear iniciativas que visem remover ou descaracterizar direitos constitucionalmente protegidos.

\section{AGRADECIMENTOS}

Cumpre agradecer o apoio para a realização deste trabalho do Programa de Pós-graduação em Gestão de Organizações Públicas da Universidade Federal de Santa Maria e do Projeto de Pesquisa: FORMAÇÃO DE BANCO DE DADOS DOS INSTRUMENTOS DE PLANEJAMENTO URBANO - Número do projeto. 054819 através do apoio da bolsista Verônica Graeff que auxiliou na revisão e 
formatação do artigo e ao Instituto Brasileiro de Direito Urbanístico - IBDU pela oportunidade de promover e discutir com entidades e sociedade as Notas Técnicas sobre os temas tratados neste artigo.

\section{CONFLITO DE INTERESSES}

"Não possui conflito de interesses".

\section{REFERÊNCIAS}

BRASIL. [Constituição (1988)]. Constituição da República Federativa do Brasil de 1988. Brasília, DF: Presidência da República, [2016]. Disponível em: http://www.planalto.gov.br/ccivil_03/Constituicao/ Constituiçao.htm.. Acesso em 10/08/2021.

BRASIL. LEI No 6.766, DE 19 DE DEZEMBRO DE 1979. Dispõe sobre o Parcelamento do Solo Urbano e dá outras Providências. Disponível em http://www.planalto.gov.br/ccivil_03/leis/16766.htm . Acesso em 20 de setembro de 2021. 1979.

BRASIL. Lei 10.257, de 10 de julho de 2001. Estatuto da Cidade. Disponível em: http://www.planalto. gov.br/ccivil_03/leis/leis_2001/110257.htm Acesso em 20 set.2021. 2001

BRASIL. LEI No 12.651, DE 25 DE MAIO DE 2012. Dispõe sobre a proteção da vegetação nativa; altera as Leis $n^{\circ}$ s 6.938, de 31 de agosto de 1981, 9.393, de 19 de dezembro de 1996, e 11.428, de 22 de dezembro de 2006; revoga as Leis $n^{\circ}$ s 4.771, de 15 de setembro de 1965, e 7.754, de 14 de abril de 1989, e a Medida Provisória no 2.166-67, de 24 de agosto de 2001; e dá outras providências. Disponível em http://www.planalto.gov.br/ccivil_03/_ato2011-2014/2012/lei/112651.htm Acesso em 20 set. 2021. 2012.

BRASIL. Medida Provisória no 759, de 22 de dezembro de 2016. Dispõe sobre a regularização fundiária rural e urbana, sobre a liquidação de créditos concedidos aos assentados da reforma agrária e sobre a regularização fundiária no âmbito da Amazônia Legal, institui mecanismos para aprimorar a eficiência dos procedimentos de alienação de imóveis da União, e dá outras providências. Disponível em http:// www.planalto.gov.br/ccivil_03/_ato2015-2018/2016/Mpv/mpv759.htm Acesso em 20 set. 2021. 2016

BRASIL. Lei 13.465, de 11 de julho de 2017. Dispõe sobre a regularização fundiária rural e urbana, sobre a liquidação de créditos concedidos aos assentados da reforma agrária e sobre a regularização fundiária no âmbito da Amazônia Legal; institui mecanismos para aprimorar a eficiência dos procedimentos de alienação de imóveis da União (,„,) Disponível em http://www.planalto.gov.br/ccivil_03/_ato20152018/2017/lei/l13465.htm Acesso em 10 set. 2021. 2017

BRASIL. MEDIDA PROVISÓRIA No 852, DE 21 DE SETEMBRO DE 2018. Dispõe sobre a transferência de imóveis do Fundo do Regime Geral de Previdência Social para a União, sobre a administração, a alienação e a gestão dos imóveis da extinta Rede Ferroviária Federal S.A. - RFFSA, extingue o Fundo Contingente da Extinta RFFSA - FC e dispõe sobre a gestão dos imóveis da União. Disponível em http:// www.planalto.gov.br/ccivil_03/_ato2015-2018/2018/Mpv/mpv852.htm. Acesso em 20 set. 2021. 2018

BRASIL LEI No 13.813, DE 9 DE ABRIL DE 2019. Dispõe sobre a transferência de imóveis do Fundo do Regime Geral de Previdência Social para a União, sobre a administração, a alienação e a gestão dos imóveis da extinta Rede Ferroviária Federal S.A. (RFFSA) e sobre a gestão dos imóveis da União; extin- 
gue o Fundo Contingente da Extinta RFFSA (FC), entre outras providências. Disponível em http://www. planalto.gov.br/ccivil_03/_ato2019-2022/2019/lei/L13813.htm .(2019). Acesso em 20 set. 2021. 2019.

BRASIL. LEI No 13.874, DE 20 DE SETEMBRO DE 2019. Institui a Declaração de Direitos de Liberdade Econômica; estabelece garantias de livre mercado; altera as Leis ${ }^{\text {os }} 10.406$, de 10 de janeiro de 2002 (Código Civil), 6.404, de 15 de dezembro de 1976, 11.598, de 3 de dezembro de 2007, 12.682, de 9 de julho de 2012, 6.015, de 31 de dezembro de 1973, 10.522, de 19 de julho de 2002, 8.934, de 18 de novembro 1994, o Decreto-Lei no 9.760 , de 5 de setembro de 1946 e a Consolidação das Leis do Trabalho, aprovada pelo Decreto-Lei $\mathrm{n}^{\circ} 5.452$, de $1^{\circ}$ de maio de 1943; revoga a Lei Delegada $\mathrm{n}^{\circ} 4$, de 26 de setembro de 1962, a Lei $\mathrm{n}^{\circ} 11.887$, de 24 de dezembro de 2008, e dispositivos do Decreto-Lei ${ }^{\circ}$ 73, de 21 de novembro de 1966; e dá outras providências. Disponível em http://www.planalto.gov.br/ ccivil_03/_ato2019-2022/2019/lei/L13874.htm Acesso em 15 set. 2021. 2019.

BRASIL. MEDIDA PROVISÓRIA No 915, DE 27 DE DEZEMBRO DE 2019. Disponível em http:// www.planalto.gov.br/ccivil_03/_ato2019-2022/2019/Mpv/mpv915.htm, Acesso em 20 set. 2021. 2019.

BRASIL. MINISTÉRIO DA ECONOMIA. Resolução CGSIM n. 64. Versa sobre a classificação de risco no direito urbanístico para os fins do inciso I do caput e inciso II e do $₫ 1^{\circ}$ do art. $3^{\circ}$ da Lei $n^{\circ} 13.874$ de 20 de setembro de 2019, bem como para o inciso I do art. 19 do Decreto no 10.178 , de 18 dezembro de 2019. Disponível em https://www.in.gov.br/en/web/dou/-/resolucao-cgsim-n-64-de-11-de-dezembro-de-2020-294084540. Acesso em 10 set. 2021. 2020.

BRASIL. LEI No 14.011, DE 10 DE JUNHO DE 2020, Aprimora os procedimentos de gestão e alienação dos imóveis da União; altera as Leis n os 6.015, de 31 de dezembro de 1973, 9.636, de 15 de maio de 1998, 13.240, de 30 de dezembro de 2015, 13.259, de 16 de março de 2016, e 10.204, de 22 de fevereiro de 2001, e o Decreto-Lei no 2.398, de 21 de dezembro de 1987; revoga dispositivos das Leis n os 9.702, de 17 de novembro de 1998, 11.481, de 31 de maio de 2007, e 13.874, de 20 de setembro de 2019; e dá outras providências. Disponível em http://www.planalto.gov.br/ccivil_03/_ato2019-2022/2020/lei/ L14011.htm. 2020. Acesso em 10 set. 2021. 2020.

CÂMARA DOS DEPUTADOS. Projeto de Lei 2633, 2020. Disponível em: https://www.camara.leg. br/proposicoesWeb/fichadetramitacao?idProposicao=2252589. Acesso em 30 set. 2021. 2020.

CÂMARA DOS DEPUTADOS. Projeto de Lei 413, 2020. Disponível em https://www.camara.leg.br/ propostas-legislativas/2238009. Acesso em 30 setembro de 2021. 2020.

DARDOT, Pierre e LAVAL, Christian. A nova razão do mundo: ensaio sobre a sociedade neoliberal. Rio de janeiro: Boitempo, 2016.

FELLET, João. Como a 'MP da grilagem’ pode mudar o mapa de regiões da Amazônia. BBC News Brasil. Disponível em: https://www.bbc.com/portuguese/brasil-51071810. Acesso em 10 de outubro de 2020.

INSTITUTO BRASILEIRO DE DIREITO URBANÍSTICO. Nota Técnica sobre a PEC 80-2019. (Nota 2). 2019. Disponível em: https://ibdu.org.br/notas/nota-tecnica-sobre-a-pec80-2019 
INSTITUTO BRASILEIRO DE DIREITO URBANÍSTICO. Nota Conjunta: A “BOIADA” URBANÍSTICA - Projeto de Lei pretende ataque frontal ao Estatuto da Cidade e à legislação urbana sob o subterfúgio da pandemia. IBDU. 2020a.

INSTITUTO BRASILEIRO DE DIREITO URBANÍSTICO. Nota técnica Resolução CGSIM n. 64. IBDU 2020b.

INSTITUTO NACIONAL DE COLONIZAÇÃO E REFORMA AGRÁRIA (INCRA). Tabela de índices cadastrais, 2013. Disponível em http://www.incra.gov.br/media/docs/indices_basicos_2013_por_municipio.pdf. Acesso em 10 de outubro de 2020.

OLIVEIRA, Germano. MP da Grilagem. Isto é - Brasil confidencial. Disponível em: https://istoe.com. br/mp-da-grilagem/. Acesso em 12 de outubro de 2020.

OLIVEIRA FILHO, João Telmo. A participação popular no planejamento urbano. A experiência do plano diretor de Porto Alegre. Tese de Doutorado. Programa de Pós-graduação em planejamento urbano e Regional - Propur- Universidade Federal do Rio Grande do Sul - Ufrgs, Disponível em: https:// lume.ufrgs.br/handle/10183/17328. Acesso em 02 ago 2021. 2009.

RIBEIRO, Tarcyla. Dominância financeira, regulação legal e espaço urbano: o caso da regularização fundiária no Brasil. Rio de Janeiro, RJ. Editora Letra Capital, 2021.

SENADO FEDERAL. Proposta de Emenda à Constituição n. 80, 2019. Disponível em https://www25. senado.leg.br/web/atividade/materias/-/materia/136894. Acesso em 10 ago 2021. 2019

HERMANY, Ricardo Hermany, GIACOBBO, Guilherme Estima. A nova agenda urbana e a política fundiária no Brasil entre o horizonte e o abismo: considerações sobre a proposta de emenda constitucional no 80/2019 e o esvaziamento da função social da propriedade. Revista de Direito da Cidade, vol. 12, no 4. ISSN 2317-7721. pp.2465-2485, 2020. 